\title{
Feasibility of Conducting Research in a Student Physiotherapy Clinic in Australia: A Pilot Study
}

\author{
Scott Buckerfield \\ University of South Australia, scott.buckerfield@gmail.com \\ Felicity Braithwaite \\ University of South Australia, felicity.braithwaite@mymail.unisa.edu.au \\ Julie Walters \\ University of South Australia, julie.walters@unisa.edu.au \\ Maureen P. McEvoy \\ University of South Australia, maureen.mcevoy@unisa.edu.au
}

Follow this and additional works at: https://nsuworks.nova.edu/ijahsp

Part of the Medical Education Commons, and the Other Education Commons

\section{Recommended Citation \\ Buckerfield S, Braithwaite F, Walters J, McEvoy MP. Feasibility of Conducting Research in a Student Physiotherapy Clinic in Australia: A Pilot Study. The Internet Journal of Allied Health Sciences and Practice. 2019 Jan 01;17(2), Article 3.}

This Manuscript is brought to you for free and open access by the College of Health Care Sciences at NSUWorks. It has been accepted for inclusion in Internet Journal of Allied Health Sciences and Practice by an authorized editor of NSUWorks. For more information, please contact nsuworks@nova.edu. 


\title{
Feasibility of Conducting Research in a Student Physiotherapy Clinic in Australia: A Pilot Study
}

\begin{abstract}
Purpose: Allied health student clinics are growing in number and scope, providing a potential untapped avenue for clinical research. The aim of this pilot study was to assess the feasibility of conducting a longitudinal research study over four sessions in a student physiotherapy clinic under the supervision of registered physiotherapists as clinical educators.

Method: This feasibility study gathered data on recruitment in a designated time period, attendance rates and adherence of participants to the treatment, with evaluation also of the acceptability of the entire protocol to participants (patients, students, clinical educators) and to the research team.

Results: Data were collected over 12 weeks. Surveys providing feedback on the acceptability of the study protocol were completed by six of the 18 patients, nine of the 12 students, and four of the seven clinical educators. All patient participants felt that the student clinic was an appropriate research site and none considered the study protocol disruptive or intrusive of their time. Students reported that the study protocol did not increase their workload or impose major barriers to treatment or building rapport with patients.

Conclusion: While conducting research in a student clinic is feasible, the setting may be more appropriate for cross-sectional studies. Student engagement and educational value could be maximised by integrating the research into curriculum.
\end{abstract}

\section{Author Bio(s)}

Scott Buckerfield BPhty(Hons) graduated from the University of South Australia in 2016. He is currently working full-time as a musculoskeletal physiotherapist and maintains a keen interest in evidence-based practice.

Julie Walters BAppSc, PhD is a lecturer in physiotherapy at the University of South Australia. Her research interests include headache, osteoarthritis, and clinical education. She primarily works in the musculoskeletal discipline of physiotherapy.

Felicity Braithwaite BPhty(Hons) is a physiotherapist and PhD candidate at the University of South Australia. She works in the musculoskeletal discipline of physiotherapy, and her research interests include physical interventions, blinding and placebo effects.

Maureen McEvoy MAppSc(Phty), PhD is a lecturer and researcher in musculoskeletal physiotherapy, clinical education and evidence-based practice. She works primarily as a lecturer and clinical educator in a University outpatient clinic with fourth year students.

\section{Acknowledgements}

The authors would like to acknowledge and thank the students, clinical educators and patients who participated in the study and the receptionist at the University of South Australia student physiotherapy clinic for her assistance during the study. 


\title{
1IJAHSP \\ The Internet Joumnal of Allied Health Sciences and Practice \\ Dedicated to allied health professional practice and education
}

Vol. 17 No. 2 ISSN 1540-580X

\section{Feasibility of Conducting Research in a Student Physiotherapy Clinic in Australia: A Pilot Study}

\author{
Scott Buckerfield \\ Felicity Braithwaite \\ Julie Walters \\ Maureen P. McEvoy \\ University of South Australia \\ Australia
}

\begin{abstract}
Purpose: Allied health student clinics are growing in number and scope, providing a potential untapped avenue for clinical research. The aim of this pilot study was to assess the feasibility of conducting a longitudinal research study over four sessions in a student physiotherapy clinic under the supervision of registered physiotherapists as clinical educators. Method: This feasibility study gathered data on recruitment in a designated time period, attendance rates, and adherence of participants to the treatment, with evaluation also of the acceptability of the entire protocol to participants (patients, students, clinical educators) and to the research team. Results: Data were collected over 12 weeks. Surveys providing feedback on the acceptability of the study protocol were completed by 6 of the 18 patients, 9 of the 12 students, and 4 of the 7 clinical educators. All patient participants felt that the student clinic was an appropriate research site and none considered the study protocol disruptive or intrusive of their time. Students reported that the study protocol did not increase their workload or impose major barriers to treatment or building rapport with patients. Conclusion: While conducting research in a student clinic is feasible, the setting may be more appropriate for cross-sectional studies. Student engagement and educational value could be maximised by integrating the research into the curriculum.
\end{abstract}

Keywords: feasibility, student clinic, undergraduate, clinical education, physiotherapy, research, recruitment, attendance 


\section{INTRODUCTION}

Student clinics based at, or run by, a university are increasingly being established to enable completion of compulsory curriculum requirements for allied health registration.1,2 These clinics have been variably called "student-led", "studentassisted," and "student-organised" clinics. The term "student clinic" is used here to encompass all clinics where the services are delivered by students under the supervision of registered practitioners, and where involvement or experience in the clinic is part of the curriculum for completion of a university program. Volunteer clinics are not included in this definition.

A driving factor behind the establishment of student clinics in Australia was the provision of clinical placements. ${ }^{2}$ However, the role of student clinics has broadened over time in response to changes in healthcare delivery; educational literature reports that student clinics have contributed to improving access to primary care services for disadvantaged clients, improving interprofessional understanding and social accountability of students, and developing students' leadership and responsibility.3.5 There is also potential for student clinics to be used in research; where this has been reported, student involvement has varied. Students were recruited as participants, helped conduct the research, or were not involved at all, with the clinic used for recruitment only. Few studies using clinics for research required patients to attend more than one treatment session, and to our knowledge, there are no published studies evaluating the feasibility of conducting research in a student clinic.

Using student clinics for research may have the additional benefit of exposing students to clinical research, giving greater context to the notion of evidence based practice - a strong focus of current undergraduate allied health programs in Australia. ${ }^{6}$ Improved context and understanding of research by undergraduates who choose not to undertake additional research training through honours or masters level study, may result in earlier uptake in clinical practice or greater likelihood of participating following graduation, so that research will progress even where funding is limited.

Feasibility studies estimate and test the parameters of the study design such as recruitment rates, attendance rates, and the appropriateness of outcome measures. ${ }^{7,8}$ Importantly, feasibility studies typically do not focus on evaluation of the clinical outcomes, which are left to follow-up studies. Acceptability may be incorporated into or separated from the concept of feasibility. Acceptability for the current study is adapted from the definition used in interventions and relates to perceived and practical aspects of the appropriateness of the protocol by the people delivering or receiving it. ${ }^{9}$

The primary purpose of this pilot study was to assess the feasibility of conducting a longitudinal research study in a clinic where services are delivered by final year physiotherapy students under the supervision of registered practitioners (clinical educators). The focus of the feasibility was to determine if participants can be recruited in a designated time period, to determine attendance and adherence of participants to the treatment, and to evaluate the acceptability of the protocol; the acceptability related to the participants (patients, students, clinical educators) and to the research team of the entire protocol.

\section{METHODS}

Design

This pilot study was designed as a feasibility study, gathering data on recruitment rates, attendance rates, the appropriateness of the setting, and the acceptability of the research protocol. The principal investigator conducted a pilot study measuring bilateral hamstring length (based on a hypothesised relationship with low back pain).10,11 The hamstring measurement will not be described and the results will not be presented, as it was the feasibility of introducing a research protocol that was the focus of this study. Ethical approval was obtained from the Health Sciences Divisional Human Research Ethics Committee, at the University of South Australia (Ethics protocol number: 0000034346)

\section{Setting}

The pilot study was conducted at the University of South Australia student physiotherapy clinic, which provides 6 rotational 5week clinical placements across the year for final year students in the undergraduate Bachelor of Physiotherapy program. Services are provided to the general public with or without referral, for a nominal administration fee.

The student clinic is open from $8 \mathrm{am}$ to $5 \mathrm{pm}$ on weekdays, and staffed by up to 15 students per five week rotation. Supervision is provided by six clinical educators and overall clinic management is provided by one receptionist. Time allocated to each patient appointment varies from 30 to 60 minutes. During each appointment, the student conducts a patient interview, physical assessment, and treatment. Between each phase of the appointment (interview, assessment, treatment), the student briefly leaves the patient and discusses the presentation and plans with the clinical educator.

\section{Participants}

There were 3 participant groups in the pilot study: patients, students, and clinical educators. Students $(n=58)$ were final year undergraduate physiotherapy students over 4 of the 5 -week rotation clinical placements; clinical educators $(n=7)$ were physiotherapists registered with the Australian Health Practitioner Registration Agency (AHPRA); patients were adults with non-irritable LBP present for $>2$ weeks and reduced hamstring length (knee extension angle (KEA) $>10$ degrees). Patients 
were excluded if they had any symptoms below the gluteal fold and any lower limb neurological symptoms such as numbness, pins and needles, weakness, or altered reflexes. Eligible patients were also required to have adequate cognition and enough English language skills to understand the procedure and to provide consent. As the study was a feasibility study, there was no sample size calculation. The initial target was 30 patient participants over 2 five-week periods of data collection.

\section{Recruitment}

An email and information sheet were sent to students and clinical educators by a member of the research team a week before the clinical placement commenced, and questions were answered at a pre-clinical placement teaching session. Patients presenting with LBP identified as potential participants while making phone appointments or on arrival at the University clinic were approached in the waiting room by the principal investigator who provided an information sheet to be read while awaiting a first appointment.

\section{Eligibility}

The treating student or the clinical educator discussed the invitation to the research project with the patient. After the student completed the patient interview and left the treatment room to discuss the presentation and plan the assessment with the clinical educator, the principal investigator screened eligibility of patients who accepted the invitation for this to occur. Once eligibility was established, informed consent to participate was obtained and baseline hamstring length measurements were recorded by the principal investigator.

\section{Procedure}

The student then completed the physical assessment and treatment, after which the principal investigator again assessed and recorded the hamstring lengths. Students were requested to organise 3 follow-up appointments with patients, spaced as close to one week apart as possible. The timing of appointments was planned in an attempt to simulate restrictions that may be in place during larger-scale trials. At each subsequent appointment, the students conducted their routine interview, assessment, and treatment of the LBP in accordance with the presentation of the patient, and hamstring length measurements were undertaken by the principal investigator both before the treatment while the student was in discussion with the clinical educator and after the treatment was completed.

Students provided conventional LBP management in accordance with the patient's individual clinical presentation and LBP management guidelines. ${ }^{12}$ Treatments included soft tissue massage, heat, exercises, spinal manipulations, and education. As part of the protocol, there was a treatment restriction on neurodynamic mobilisations or interventions that may directly impact hamstring length (for example massage or stretching).

At the end of their involvement in the pilot study, patient, student, and clinical educator participants provided feedback on the acceptability of the protocol. Patients completed these acceptability questionnaires at discharge or the end of their fourth treatment session, students at the end of their 5-week placement, and clinical educators at the end of the data collection period. The principal investigator maintained a journal and recorded notes throughout the study related to the feasibility of the study and the acceptability of the protocol from the perspective of the research team.

Table 1: Feasibility outcome measurements template for recruitment, patient attendance, participant adherence

\begin{tabular}{ll}
\hline Recruitment & $\begin{array}{c}\text { Student and clinical educators } \\
\text { Number "staffing" the clinic } \\
\end{array}$ \\
\cline { 2 - 2 } & Number directly involved in the research \\
\cline { 2 - 3 } & Patients \\
& Number presenting with LBP \\
& Number screened for eligibility \\
& Number eligible/ ineligible (including reasons) \\
& Rates of consent to be screened \& to participate \\
& Rates of potentially eligible patients who were not identified to the principal investigator \\
& Withdrawal rates \\
\hline Participant & Number of appointments \\
Attendance & Time between appointments \\
& Rates of non-attendance \\
\hline Student & Rates of student adherence to the research protocol (including timing of \\
Adherence & appointments, identification of patients) \\
& Number of missed measurements \\
& Deviations to the treatment protocol (by students and patients) \\
\hline
\end{tabular}




\section{Outcome Measures \\ Feasibility. During the study period, a number of measures of feasibility were recorded and maintained by the principal investigator, as shown in Table 1.}

Acceptability. Separate acceptability feedback forms were purposefully developed by the research team for the students, the clinical educators, and the patients to address major areas of acceptability. The acceptability areas addressed were the appropriateness of the setting for research, the value of the participation, additional time commitment, and restrictions that participation may have placed on management decisions, the relationship with the patient, and timing of appointments. The principal investigator completed a field note journal, documenting perceptions of the appropriateness of the student clinic for research, possible barriers for future research, and potential solutions to those barriers.

\section{Data Management}

Descriptive data were collected for the recruitment, attendance, and adherence rates of participants (patients, students, and clinical educators) and protocol acceptability to patients, students, clinical educators, and the principal investigator.

\section{RESULTS}

Feasibility

Recruitment. Forty-nine patient participants were identified over 12 weeks $(2 \times 5$ week rotations plus two further weeks) as potentially eligible but 3 did not attend the first clinic visit. Of the 46 initially assessed, 23 were excluded following the interview (incorrect symptom area, irritable condition, other co-morbidities, inadequate English, not interested) and 5 were excluded based on the hamstring length measurement. Therefore, 18 participants were included in the study. Figure 1 presents a flowchart of the recruitment and eligibility of participants in the study.

Eight females and 10 males were recruited as patient participants. The age of the participants ranged from 19 to 65 years with a mean [standard deviation (SD)] age of 33.88 (16.2) years. In all but one case, the patient was treated by the same physiotherapy student throughout participation in the study.

Seven clinical educators supervised across the duration of the study period; all 7 were involved in recruitment and/or management of patients in the study.

A total of 58 students participated in a clinical placement at the student clinic during data collection. However, 30 of these were involved for just one week of data collection: 15 in the final week of a clinical placement and 15 in the first week of a clinical placement; these two single weeks bookended the main $2 \times 5$ week placement groups involving 28 students where most data was collected. Twelve students provided treatment for patients involved in the research.

Patient attendance. The mean (SD) number of sessions for the 18 patients was 2.33 (1.15). Four patients completed all four planned treatment sessions and 6 did not return following their first treatment session. Reasons provided for the 14 participants who did not complete all four treatment sessions (ie, non-attendance or withdrawing from the study) were that patients no longer required treatment $(n=7)$, were unable to book another appointment $(n=2)$, and the student and clinical educator felt that lower limb treatment was needed $(n=1)$. Four patients could not be contacted to provide reasons for their withdrawal. The mean (SD) time between sessions was 7.29 (4.88) days (range 2 to 22 days).

Participant adherence to the protocol. In 84 intended measurements (with two planned per participant attendance), a total of $11(13 \%)$ measurements were missed due to the principal investigator being unavailable $(n=7)$, students failing to advise the principal investigator that the patient was available for measurement $(n=2)$, and patients being unable to stay for measurement following their appointment $(n=2)$.

Deviations from the protocol occurred for four patients who were prescribed hamstring stretches $(n=3)$ and hamstring strengthening exercises $(n=1)$ contrary to the research protocol. 


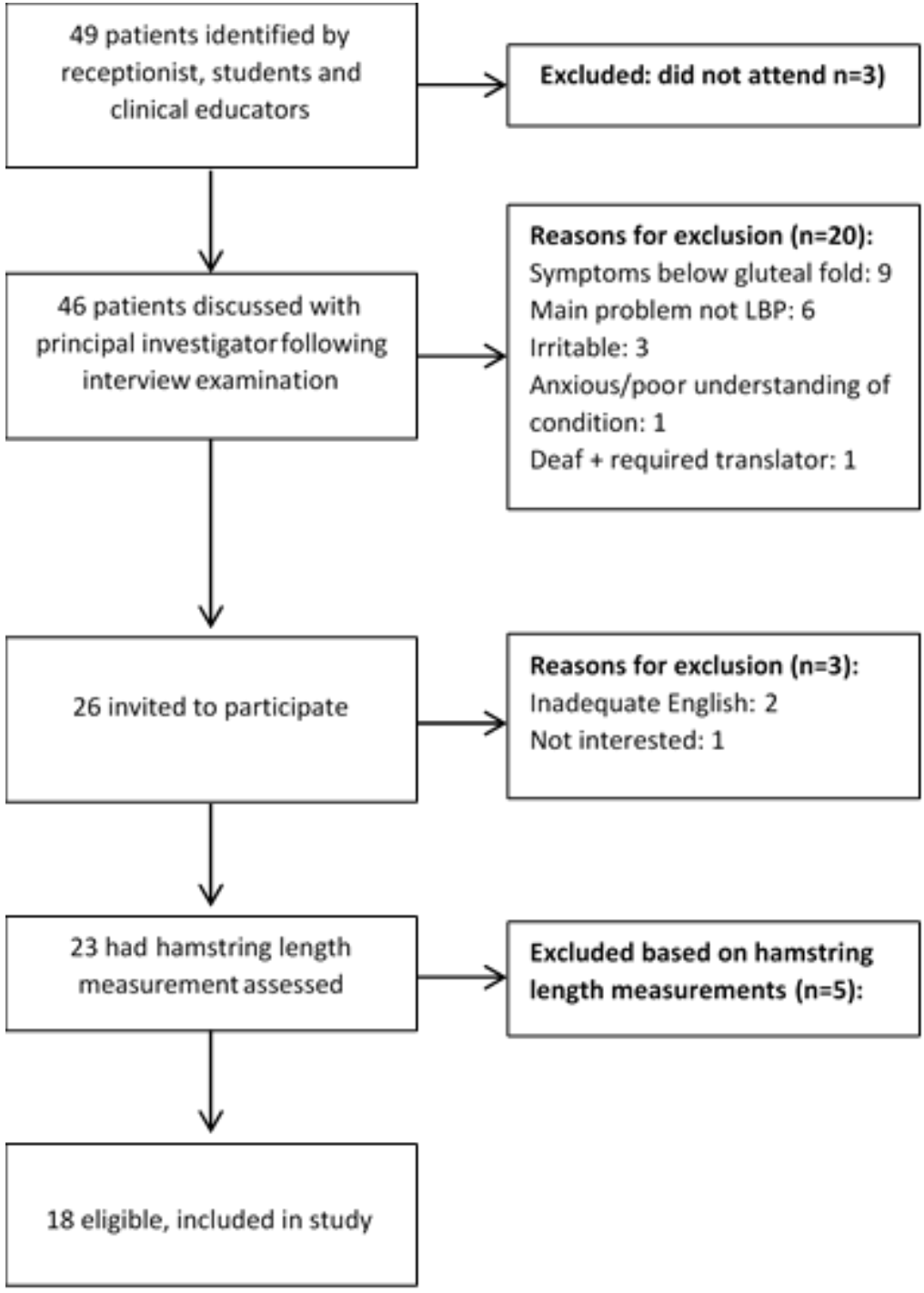

Figure 1. Recruitment and eligibility of participants

Table 2. Patient perspectives on research being conducted in the student clinic $(n=6)$.

\begin{tabular}{|c|c|c|c|c|c|}
\hline $\begin{array}{c}\text { Was the process } \\
\text { acceptable (/10) }\end{array}$ & $\begin{array}{c}\text { Comments on } \\
\text { appropriateness of site }\end{array}$ & - & $\begin{array}{c}\text { Was it } \\
\text { disruptive? }\end{array}$ & $\begin{array}{c}\text { Were delays } \\
\text { caused? }\end{array}$ & Other comments \\
\hline 10 & - & $\mathrm{N}$ & $\mathrm{N}$ & - \\
\hline 10 & $\begin{array}{c}\text { Provides opportunity to } \\
\text { find relationships between } \\
\text { problem \& alternatives }\end{array}$ & $\mathrm{N}$ & $\mathrm{N}$ & - \\
\hline 8 & $\begin{array}{c}\text { Helps develop young, } \\
\text { successful professionals }\end{array}$ & $\begin{array}{c}\text { Students may have new or } \\
\text { innovative ideas }\end{array}$ & $\mathrm{N}$ & $\mathrm{N}$ & - \\
\hline 10 & $\begin{array}{c}\text { Enables students to learn; } \\
\text { become better } \\
\text { professionals }\end{array}$ & & $\mathrm{N}$ & $\mathrm{N}$ & $\begin{array}{c}\text { Equipment was } \\
\text { cumbersome }\end{array}$ \\
\hline 10 & $\quad \begin{array}{c}\text { Interesting to see } \\
\text { the differences } \\
\text { each time }\end{array}$ \\
\hline
\end{tabular}

$\mathrm{N}=$ no 
All student participants felt that the student clinic was an appropriate research site. Students reported that the study protocol did not increase their workload or impose major barriers to treatment or building rapport with patients. Of those who commented $(n=9)$, most students reported that participating in the research was valuable to them $(n=6)$; for the remaining 3 students, the patients either attended one session only resulting in no opportunity to observe changes $(n=2)$, or the student cited minimal involvement due to being out of the room when the measurements were taken $(n=1)$. In these situations, the students did not feel involved in the research. Acceptability ratings and further comments are presented in Table 3.

Table 3. Student perspectives on research being conducted in the student clinic $(n=9)$.

\begin{tabular}{|c|c|c|c|}
\hline $\begin{array}{l}\text { Was the process } \\
\text { acceptable }(/ 10)\end{array}$ & $\begin{array}{l}\text { Comments on } \\
\text { appropriateness of site }\end{array}$ & $\begin{array}{l}\text { Were delays } \\
\text { caused? }\end{array}$ & $\begin{array}{c}\text { Comments on value of the } \\
\text { experience? }\end{array}$ \\
\hline 9 & $\begin{array}{c}\text { Access to patients who } \\
\text { spend time waiting }\end{array}$ & Mostly N & $\begin{array}{c}\text { Always out of the room - not really } \\
\text { involved in the study }\end{array}$ \\
\hline 10 & 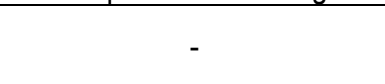 & $\mathrm{N}$ & $\begin{array}{c}\text { It helps to have a second opinion } \\
\text { about the test }\end{array}$ \\
\hline 10 & $\begin{array}{c}\text { Easy to do before \& after } \\
\text { appointment }\end{array}$ & $\mathrm{N}$ & $\begin{array}{l}\text { Interested to see if there is a link } \\
\text { between tight hamstrings \& LBP }\end{array}$ \\
\hline 10 & $\begin{array}{c}\text { Easy to do with CEs \& } \\
\text { students }\end{array}$ & Slight & (2) \\
\hline 10 & $\begin{array}{c}\text { No impact on students; } \\
\text { mostly not present }\end{array}$ & $\mathrm{N}$ & $\begin{array}{c}\text { Only had } 2 \text { patients: both only had } 1 \\
\text { treatment. }\end{array}$ \\
\hline 10 & $\begin{array}{c}\text { There is enough time to add } \\
\text { research }\end{array}$ & $\mathrm{N}$ & $\begin{array}{c}\text { Only had } 1 \text { session; patient DNR so } \\
\text { we didn't see any changes }\end{array}$ \\
\hline 10 & $\begin{array}{c}\text { Easy access to people with } \\
\text { LBP }\end{array}$ & $\mathrm{N}$ & $\begin{array}{c}\text { Interesting to see if treatment had an } \\
\text { effect on hamstring length }\end{array}$ \\
\hline 10 & $\begin{array}{l}\text { Easy to find patients who are } \\
\text { willing to participate }\end{array}$ & $\mathrm{N}$ & Insight into Honours research \\
\hline 9 & Lots of patients & $\mathrm{N}$ & Minimal involvement but valuable \\
\hline
\end{tabular}

CEs clinical educators; $\mathrm{N}=$ no; $\mathrm{LBP}=$ low back pain; $\mathrm{DNR}=$ did not return

Clinical educators were generally happy with the protocol; all 4 respondents felt that the student clinic was an appropriate research site. Clinical educators generally felt that the protocol did not interfere with student learning or cause major disruptions. No clinical educator reported that the study affected students' ability to build rapport with their patients. Acceptability ratings and further comments and suggestions are presented in Table 4.

Table 4: Clinical educator perspectives on research being conducted in student clinic $(n=4)$

\begin{tabular}{|c|c|c|c|c|}
\hline $\begin{array}{l}\text { Was the } \\
\text { process } \\
\text { acceptable } \\
(/ 10) \\
\end{array}$ & $\begin{array}{l}\text { Comments on } \\
\text { appropriateness of site }\end{array}$ & $\begin{array}{l}\text { Were } \\
\text { delays } \\
\text { caused? }\end{array}$ & $\begin{array}{l}\text { Comments on } \\
\text { value of the } \\
\text { experience? }\end{array}$ & Other comments \\
\hline 10 & $\begin{array}{l}\text { Minimal impact, clinic provides } \\
\text { easy access to patients }\end{array}$ & $\mathrm{N}$ & $\begin{array}{c}\text { Minimal } \\
\text { involvement }\end{array}$ & - \\
\hline 8 & $\begin{array}{c}\text { Patients like contributing to } \\
\text { student learning. } \\
\text { They know it is a learning } \\
\text { institution }\end{array}$ & $\begin{array}{l}\text { Sometimes; } \\
\text { time is } \\
\text { already a } \\
\text { challenge }\end{array}$ & $\begin{array}{c}\text { Could add a } \\
\text { sense of vibrancy } \\
\text { \& unification to } \\
\text { students }\end{array}$ & $\begin{array}{l}\text { Sometimes } \mathrm{Ax} \& \mathrm{Mx} \text { of } \mathrm{H} / \mathrm{S} \\
\text { may have been appropriate. } \\
\text { Some time pressure. }\end{array}$ \\
\hline 8 & $\begin{array}{l}\text { The student clinic is ideal to } \\
\text { learn research \& non-clinical } \\
\text { skills, as well as see } \\
\text { patients }\end{array}$ & $\mathrm{N}$ & $\begin{array}{l}\text { Minimal } \\
\text { involvement }\end{array}$ & - \\
\hline 9 & $\begin{array}{l}\text { Good access to patients. } \\
\text { Exposes students to research } \\
\text { \& presents opportunity for } \\
\text { involvement (\& ideas for } \\
\text { future research) }\end{array}$ & $\mathrm{N}$ & $\begin{array}{l}\text { Minimal } \\
\text { involvement }\end{array}$ & $\begin{array}{l}\text { Few restrictions to } M x \text {. } \\
\text { Consider length of } \\
\text { appointments - other studies } \\
\text { might not be as efficient. }\end{array}$ \\
\hline
\end{tabular}

$\mathrm{Ax}=$ assessment; $\mathrm{Mx}=$ management; $\mathrm{H} / \mathrm{S}$ = hamstring 
Acceptability of the study to the principal investigator. The field note journal completed by the principal investigator was used to record the acceptability of the study, barriers to future research in the student clinic environment, and potential strategies to address those barriers. A summary of the key points from this is presented in Table 5 .

Table 5. Key points from principal investigator's reflective summary

\begin{tabular}{|l|l|}
\hline Domain & Summary \\
\hline Recruitment & $\begin{array}{l}\text { Because patients often arrived just before the appointment \& there was other routine } \\
\text { paperwork to complete, there was often insufficient time to discuss the project with them } \\
\text { prior to their appointment }\end{array}$ \\
\hline Time efficiency & $\begin{array}{l}\text { Overall, study was generally time-efficient } \\
\text { Students are often slow with assessments \& treatment, \& where patients were short of } \\
\text { time, post-treatment measurements were difficult to complete }\end{array}$ \\
\hline $\begin{array}{l}\text { Adherence } \\
\text { (of students and } \\
\text { educators) }\end{array}$ & $\begin{array}{l}\text { Students \& clinical educators are very busy \& focussed on their placements; participation } \\
\text { in the research appeared to be of secondary importance } \\
\text { Students required many reminders/cues from the principal investigator to fully participate }\end{array}$ \\
\hline $\begin{array}{l}\text { Attendance } \\
\text { (of patients) }\end{array}$ & $\begin{array}{l}\text { Most did not complete all four allocated treatments } \\
\text { High levels of non-attendance are common at student clinics }\end{array}$ \\
\hline Time commitment & $\begin{array}{l}\text { Principal investigator was required to be on-site full-time because of unpredictability of } \\
\text { patient presentations \& poor understanding of the protocol by students } \\
\text { No permanent workspace and busy environment made it difficult to complete other work in } \\
\text { clinic }\end{array}$ \\
\hline
\end{tabular}

\section{DISCUSSION}

The pilot study aimed to assess the feasibility of conducting a longitudinal research study in a student clinic from the perspective of patients, students, clinical educators, and the principal investigator. This is the first known study to investigate this despite an informal audit conducted by the authors (August 2016) identifying 10 student physiotherapy clinics in Australia (from 19 physiotherapy schools). Results of the pilot study suggest that while it is feasible to conduct research in this environment, there are some specific issues that may need to be addressed before routine inclusion of research in student clinics.

Overall, with the exception of the principal investigator who reported the high burden of the research, the impact of involvement in the research was reportedly minimal for all other participants; however, this minimal impact may reflect a lack of engagement from students (only 12 of 58 students identified a potential patient, and 9 of 12 completed the post-study survey) and patients (14 of 18 missed at least 1 of 4 planned appointments). The lack of student engagement reported by the principal investigator was identified in students' poor understanding of the project, high non-attendance rates, and the need for frequent reminders about the research. The current study was the first time students in the student clinic were involved in research, so there is not currently a culture for this type of engagement; furthermore, participation was not linked to curriculum or assessment, making it of secondary importance compared to managing patients. It is plausible that changes to encourage greater engagement amongst the student group would reduce the burden felt by the principal investigator in future research.

Two previous studies conducted in student clinics reported on recruitment rates for student participants. Hermesch et al invited 100 students $(n=80)$, faculty $(n=15)$, and staff $(n=5)$ to voluntarily complete preference questionnaires with $66(66 \%)$ agreeing to be involved, but there was no separation of the student recruitment; this recruitment may have ranged from a minimum of $70 \%(46 / 66)$ to a maximum of $100 \%(66 / 66) .{ }^{13}$ Interestingly, in Repka et al, $100 \%$ of students were recruited to a mandatory audit activity that contributed $5 \%$ to their course assessment mark. ${ }^{14}$ Exact data were not available for the recruitment of students in the current study as some students reportedly were not allotted any eligible patients, so the study design, pilot nature, and short time-frame may have contributed to the low rate of student involvement.

Despite questioning their engagement, all participant groups (students, clinical educators, patients) in the current study felt that the student clinic was an appropriate site for research, and that the protocol used was acceptable. General consensus appeared to be that at worst, exposure to research did not detract from learning clinical skills, and at best, it was important to enable students to become "better professionals." Patients are aware of the additional time available in the student clinic, know the importance of this in clinical training of health professionals, and are often more understanding of delays and interruptions. ${ }^{15}$ These aspects may suggest further benefits of the student clinic environment for research that may not exist in a private clinic, where schedules are much tighter. 
Another, albeit common, issue to consider when conducting research in a student clinics is patient recruitment. A priori examination of patient visits to the clinic suggested that 10 weeks should have been sufficient to recruit 30 patients with low back pain but no neurological compromise. In reality, although 49 potential patients were identified and gave consent for assessment, only 18 were enrolled in the study. This may be due to the requirement for a KEA of 10 degrees implemented in this study, but larger studies are likely to have similar if not greater limitations on inclusions, so recruitment should be considered in the planning. This is particularly important in study environments where the recruitment effectively occurs via third parties (ie, receptionist, students, clinical educators). Adding to recruitment constraints, student clinics often provide services to patients from lower socioeconomic backgrounds; ${ }^{15-18}$ in this demographic there are frequently higher rates of nonattendance which may impact on outcomes..$^{19}$

Three previous studies conducted in student clinics reported recruitment rates for patient participants, ranging from 83 to 94 per cent of those approached. ${ }^{20-22}$ The recruitment related to patients in a waiting room invited to complete perceived health questionnaires where the recruitment rate was highest, to questionnaires sent to a specific number of eligible recipients 1 to 6 months after treatment with $83 \%$ recruitment. ${ }^{21,22}$ Diehl et al also reported strong recruitment (87\%) for follow-up interviews six months after treatment delivery. ${ }^{20} \mathrm{~A}$ comparable $94 \%$ of patients identified in the current study provided consent to be screened for eligibility, suggesting that patients who attend student clinics for treatment are generally also willing to participate in research studies when eligible.

Four previous studies conducted in student clinics have reported on attendance or adherence rates.1,20,23,24 In these studies, between 77 and 100 per cent of patient participants completed the studies and were available for up to three or four occasions of testing over periods ranging from six weeks to five years after the initial session. The greatest adherence involved single item visual analogue scale (VAS) symptom rating over a period of development of denture treatment, but rates were also high $(97 \%)$ for evaluation of dental outcome measures on four occasions over 18 weeks in a cross-over trial of two treatment approaches. 23,24 Impressive also was the $77 \%$ of participants available for interviews 18 months after treatment in Diehl et al and the $68 \%$ of stutterers who provided home telephone voice samples for analyses at follow-up 3.5 to 5 years after commencement of a study with $44 \%$ also returning a self-report inventory. ${ }^{1,20}$ These rates are considerably higher than in the current study, where only $22 \%$ of patient participants completed the four-week treatment program. The current study location was within the framework of an active student clinic, the patients recruited continued to pay (albeit a nominal amount) for treatment received and the study did not contribute directly to the patient management. It may be that patients were less invested in the study for these reasons and furthermore patients may have noted the lack of direct involvement in the research of the student therapists providing the treatment.

There are several limitations associated with this pilot study. As previously noted, only 12 of the 58 student participants provided patient participants with nine giving comments about the feasibility. All seven clinical educator participants consented to participate, but only four completed feasibility questionnaires. In addition, there was a lack of substantial and thoughtful feedback from some participants during the study. This related to students, who were often busy with administrative and assessment tasks when not treating patients, and to clinical educators, who often needed to leave immediately after the clinic to attend meetings or a second place of work. Patients often had more time available, but there was some unpredictability about the progression of their condition and the return timeframes for subsequent appointments.

There was potential for reporter bias in the feedback provided, with issues noticed by the principal investigator (eg, administration, time efficiency) sometimes not reported by participants. This may be due to reluctance in criticising a peer or be further evidence of a lack of engagement in the process overall. Patients can also be disinclined to voice dissatisfaction with student services for fear of negatively influencing their assessment or may not want to criticise clinicians with whom they have established a relationship.20,25 Finally, the clinical question chosen for this feasibility study did not provide as large a sample as anticipated; while anecdotally clinicians often report tight hamstring muscles accompanying LBP, only 18 of the 49 potential participants were ultimately eligible. ${ }^{26}$

The findings of this pilot study may be less applicable to student clinics of other health professions or volunteer clinics, which commonly exist outside of Australia. Differences in operations in these clinics such as the frequency of appointments, purpose, degree of supervision, and number of treatments patients receive may impact on feasibility of these clinics for research.

\section{CONCLUSION}

Preliminary findings from this pilot study suggest that conducting research in student clinics is feasible. Some of the identified challenges may be minimised with proactive administrative and organisational measures, such as emailing participant information sheets and limiting clinic closure times during non-teaching periods. Research studies that require patients to attend only one session may be more suitable than longitudinal designs, and student engagement could be improved by making participation more valuable either as a learning experience or part of assessment. Further research evaluating the 
feasibility of conducting research in student clinics for other health professional programs, and evaluation of research involving a single student clinic visit would be beneficial.

\section{REFERENCES}

1. Block S, Onslow M, Packman A, Gray B, Dacakis G. Treatment of chronic stuttering: Outcomes from a student training clinic. Int J Lang Commun Disord. 2005;40:455-466. [PMID: 16195200]

2. Kent $F$, Drysdale $P$, Martin N, Keating, JL. The mixed-discipline aged-care student clinic: an authentic interprofessional learning initiative. J Allied Health. 2014;43:51-56. [PMID: 24598900]

3. Buckley E, Vu T, Remedios L. The REACH project: implementing interprofessional practice at Australia's first studentled clinic. Educ Health. 2014;27:93-98. [PMID: 24934957]

4. Holmqvist M, Courtney C, Meili R, Dick A. Student-run clinics: opportunities for interprofessional education and increasing social accountability. J Res Interprof Pract Educ. 2012;2:264-277.

5. Kent $F$, Keating J. Patient outcomes from a student-led interprofessional clinic in primary care. J Interprof Care. 2013;27:336-338. [PMID: 23421346]

6. Dizon JM, Grimmer-Somers K, Kumar S. Current evidence on evidence-based practice training in allied health: a systematic review of the literature. Int J Evid Based Healthc. 2012;10:347-360. [PMID: 23173659]

7. Arain M, Campbell MJ, Cooper CL, Lancaster GA. What is a pilot or feasibility study? A review of current practice and editorial policy. BMC Med Res Methodol. 2010;10:67. [PMID: 20637084]

8. Thabane L, Ma J, Chu R, Cheng J, Ismaila A, et al. A tutorial on pilot studies: the what, why and how. BMC Med Res Methodol. 2010;10:1. [PMID: 20053272]

9. Sekhon M, Cartwrightt M, Francis JJ. Acceptability of healthcare interventions: an overview of reviews and development of a theoretical framework. BMC Health Services Research. 2017;17(1):88. [PMID: 28126032]

10. Mellin G. Correlations of hip mobility with degree of back pain and lumbar spinal mobility in chronic low-back pain patients. Spine. 1998;13:668-670. [PMID: 2972070]

11. Hultman G, Saraste H, Ohlsen $H$. Anthropometry, spinal canal width, and flexibility of the spine and hamstring muscles in 45-55-year-old men with and without low back pain. J Spinal Disord. 1992;5:245-253. [PMID: 1387820]

12. Australian Acute Musculoskeletal Pain Guidelines Group. Evidence-Based Management of Acute Musculoskeletal Pain: A Guide for Clinicians. Bowen Hills (Australia): Australian Academic Press Pty.; 2003.

13. Hermesch CB, Spackman GK, Dodge WW, Salazar A. Effect of powder-free latex examination glove use on airborne powder levels in a dental school clinic. J Dent Educ. 1999;63:814-820. [PMID: 10608927]

14. Repka A, Ebrall P, Draper B. Failure to use vertebral subluxation complex as a diagnostic term: a flaw of reductionistic diagnosis with resultant compromise of student and patient outcomes in chiropractic teaching clinics. Chiropr J Aust. 2007;37:84-91.

15. Bostick G, Hall M, Miciak M. Novel clinical learning from a student-led clinic. Clin Teach. 2014;11:512-515. [PMID: 25417978]

16. Mattheos N, Storrs M, Foster L, Oberholzer T. Intraprofessional, team-based treatment planning for oral health students in the comprehensive care clinic. J Dent Educ. 2012;76:1589-99. [PMID: 23225678]

17. Sick B, Sheldon L, Ajer K, Wang Q, Zhang L. The student-run free clinic: an ideal site to teach interprofessional education? J Interprof Care. 2014;28:413-418. [PMID: 24749742]

18. Pammett R, Landry E, Weidmann AE, Jorgenson D. Interprofessional student-run primary health care clinics: Educational experiences for pharmacy students. Can Pharm J. 2015;148:125-128. [PMID: 26150883] 
19. Gurol-Urganci I, de Jongh T, Vodopivec-Jamsek V, Atun R, Car J. Mobile phone messaging reminders for attendance at healthcare appointments. Cochrane Database Syst Rev. 2013;(12):CD007458. doi: 10.1002/14651858.CD007458.pub3. [PMID: 24310741]

20. Diehl RL, Foerster U, Sposetti VJ, Dolan TA. Factors associated with successful denture therapy. J Prosthodont. 1996;5:84-90. [PMID: 9028209]

21. Pitiphat W, Garcia RI, Douglass CW, Joshipura KJ. Validation of self-reported oral health measures. J Public Health Dent. 2002;62:122-128. [PMID: 11989207]

22. Seferli J, Michelin M, Klinge B, Wettergren L. Patients' experiences of dental implant placement for treatment of partial edentulism in a student clinic setting. Swed Dent J. 2014;38:77-85. [PMID: 25102718]

23. Lamb DJ, Ellis B. Patient-assessed security changes when replacing mandibular complete dentures. Int J Prosthodont. 1995;8:135-142. [PMID: 7575964]

24. Lie T, Enersen M. Effects of chlorhexidine gel in a group of maintenance-care patients with poor oral hygiene. $J$ Periodontol. 1986;57:364-369. [PMID: 3459860]

25. Barron DN, West E, Reeves R, Hawkes D. It takes patience and persistence to get negative feedback about patients' experiences: a secondary analysis of national inpatient survey data. BMC Health Serv Res. 2014;14:153. [PMID: 24708612]

26. Nourbakhsh MR, Arab AM. Relationship between mechanical factors and incidence of low back pain. J Orthop Sport Phys. 2002;32:447-460. [PMID: 12322811] 